Jin Luo, Yanhua Wang, Rong Ren, Weilin Sun* and Zhiquan Shen

\title{
Layer-by-layer self-assembly for controlled magnetic multilayer thin film fabrication
}

\begin{abstract}
The copolymer poly[4'-(4-methacryloyphenyl)2,2':6',2"'-terpyridine -co- $N$-(vinylbenzylimino)-diacetic acid] [P(mPhtpy-co-vbda)] was synthesized by the RAFT (reversible addition fragmentation chain transfer) polymerization method and confirmed by Fourier transform infrared spectroscopy and ${ }^{1} \mathrm{H}$ nuclear magnetic resonance spectroscopy. The bimetallic complexes of the copolymer were prepared by chelating with $\mathrm{Nd}^{3+}$ and $\mathrm{Co}^{2+}$. The magnetic multilayer film was fabricated via layer-by-layer (LbL) self-assembly with the copolymer and metal ions $\left(\mathrm{Nd}^{3+}\right.$ and $\mathrm{Co}^{2+}$ ). Attenuated total reflectance-infrared spectroscopy and UV-Vis spectroscopy were used to characterize the film, indicating that the driving force for fabricating the multilayer film was the coordination interaction. The magnetic behavior of the complexes and the film was measured as a function of the magnetic field strength $(0-$ $50 \mathrm{kOe})$ at $5 \mathrm{~K}$ and also of the temperature (5-300 K) at the magnetic field strength ( $30 \mathrm{kOe})$. The magnetic hysteresis loops of the complexes and the film showed the typical "S" shape at $5 \mathrm{~K}$, exhibiting the properties of soft ferromagnetic materials.
\end{abstract}

Keywords: bimetallic complexes; copolymer; layer-bylayer self-assembly; magnetic properties; multilayer film.

DOI 10.1515/epoly-2014-0131

Received June 26, 2014; accepted November 13, 2014; previously published online December 20, 2014

\section{Introduction}

The layer-by-layer (LbL) assembly technique, which was developed by Decher (1) in the early 1990s, is a very

\footnotetext{
*Corresponding author: Weilin Sun, MOE Key Laboratory of Macromolecular Synthesis and Functionalization, Department of Polymer Science and Engineering, Zhejiang University, Hangzhou 310027, People's Republic of China, Tel./Fax: +86 57187953727 , e-mail:opl_sunwl@zju.edu.cn Jin Luo, Yanhua Wang, Rong Ren and Zhiquan Shen: MOE Key Laboratory of Macromolecular Synthesis and Functionalization, Department of Polymer Science and Engineering, Zhejiang University, Hangzhou 310027, People's Republic of China
}

simple, efficient and inexpensive method for various fabrications of inorganic layer materials, colloid particles, multi-ionic small molecules and even proteins (2). Specifically, this technique can be used for the controlled fabrication of multilayer films based on driving forces such as electrostatic, H-bonding attraction, coordination force, charge-transfer interaction, etc. A well-established LbL multilayer film can be used with various substrates such as gold, quartz, glass, silicon, germanium, platinum and clay (3).

Magnetic polymer-metal complexes have always appealed to polymer scientists. The selected metal ions, the polymer ligand and the interaction between them respectively play important roles on the final magnetic properties. The key to obtaining an ideal magnetic polymer-metal complex is to make a complex gathered and directional arrangement. Thus, the LbL assembly technique is one of the most advanced techniques to fabricate polymer-metal complex layered thin films with precise control of film thickness and composition (4), to make such complex more effective.

$2,2^{\prime}: 6^{\prime}, 2^{\prime \prime}$-Terpyridines, which were firstly synthesized by Morgan and Burstall (5) in the 1930s, have gained much attention due to their strong coordination ability as $\mathrm{N}$-donor ligands capable of coordinating with numerous main-group, transition-metal and lanthanide cations. Their complexes exhibited distinct electrical (6), optical (7), magnetic (8) and catalytic (9) properties, giving them widespread applications in such fields as biomedical sciences (10), light-emitting electrochemical cells (LECs) (11), light-to-electricity conversion (12), etc. Furthermore, they have been used as basic components for fabricating selfassembled functional materials with nanostructures (e.g., based on gold, silver, $\mathrm{CdS}, \mathrm{TiO}_{2}$, carbon nanotubes) (13-17) as well as surfaces (e.g., glass, gold, graphite) (18-20). With the development of supramolecular chemistry in recent years, the coordinative interaction between metal ions and terpyridinyl ligands has been applied to prepare well-designed supramolecular (co)polymers with various promising properties $(21,22)$. However, among the great number of $2,2^{\prime}: 6^{\prime}, 2^{\prime \prime}$ - terpyridines and their structural analogs, the magnetic properties of terpyridine-containing LbL multilayer thin films have been seldom reported. In this paper, we report the preparation of a copolymer 
containing a terpyridinyl ring (as an $\mathrm{N}$-donor ligand) and an iminodiacetic acid (as an O-donor ligand) $(23,24)$ as well as its bimetallic complexes. We also fabricated a multilayer thin film with the copolymer and metal ions $\left(\mathrm{Nd}^{3+}\right.$ and $\left.\mathrm{Co}^{2+}\right)$ via the LbL assembly process and investigated its properties. Such magnetic multilayer thin film shows a great promise in preparing delicate magnetic devices under a complicated environment. Compared with magnetic complexes, e.g., supramolecular complexes, metal complexes containing bithiazole rings, and hyperbranched polymers containing bithiazole (25-28), the film is well organized with magnetic properties, which is significant for the development of organic magnetic applications.

\section{Experimental}

\subsection{Materials}

$N, N^{\prime}$-Dimethylformamide (DMF, laboratory suppliers) was dried using $\mathrm{CaH}_{2}$ for several days and distilled prior to use. Cobalt chloride hexahydrate $\left(\mathrm{CoCl}_{2} \cdot 6 \mathrm{H}_{2} \mathrm{O}\right)$ was purchased from Aladdin Reagent (Shanghai, China). 2,2'-Azobisisobutyronitrile (AIBN, Aladdin Reagent, Shanghai, China) was recrystallized twice with ethanol. The HDPE substrate (29), PE-COOH film (2), cumyl dithiobenzoate (CDB) (30) and neodymium trichloride hexahydrate $\left(\mathrm{NdCl}_{3} \cdot 6 \mathrm{H}_{2} \mathrm{O}\right)$ (31) were synthesized as reported.

\subsection{Measurements}

A Bruker Vector 22 Fourier transform infrared spectrometer (Bruker, Germany) was used to record the IR spectra in $\mathrm{KBr}$ pellets. ${ }^{1} \mathrm{H}$ NMR and ${ }^{13} \mathrm{C}$ NMR spectra were recorded on a Bruker Advance AMX-400NMR instrument (Bruker, Germany) in deuterated reagent with tetramethylsilane (TMS) as an internal standard. Elemental analysis for C, $\mathrm{H}$ and N was performed using a Flash EA 1112 element analyzer (Thermo Finnigan, Italy). Attenuated total reflectance infrared spectra were collected using a NicoQt 6700 spectrometer (Themo Fisher scientific LLC, USA ) equipped with an attenuated total reflectance (ATR) accessory. Molecular weights and molecular weight distributions were determined by gel permeation chromatography (GPC, Waters 1525/2414, Singapore) using THF as the eluent. Polystyrene standards were used to generate a calibration curve. The UV-Vis absorption spectra were obtained on a UV-1601
UV-Visible spectrophotometer (Varian, Co., USA). The metal $(\mathrm{Nd}, \mathrm{Co})$ contents were measured by an IRIS Intrepid II XSP inductively coupled plasma emission spectrometer (ICP, Thermo Scientific, USA). The magnetic properties of the complexes and the multilayer film were determined using a physical property measurement system (PMMS) magnetometer (PPMS-9T, Quantum Design, USA).

\subsection{Synthesis of 4'-(4-methacryloyphenyl)- $2,2^{\prime}: 6^{\prime}, 2^{\prime \prime}$-terpyridine (mPhtpy)}

4'-(4-Methacryloyphenyl)-2,2':6',2"-terpyridine was synthesized according to the literature (32) and presented as a yellow needle crystal. The yield was $0.67 \mathrm{~g}$ (85\%). m.p. 150-151 ${ }^{\circ} \mathrm{C} .{ }^{1} \mathrm{H}$ NMR $\left(400 \mathrm{MHz}, \mathrm{CDCl}_{3}, \delta, \mathrm{ppm}\right): 2.11$ (s, 3H, $\mathrm{CH}_{3}$ ), 5.84 (s, $\left.1 \mathrm{H}, \mathrm{CH}_{2}\right), 6.41$ (s, $\left.1 \mathrm{H}, \mathrm{CH}_{2}\right), 7.31$ (d, $\left.2 \mathrm{H}, \mathrm{ph}-\mathrm{H}\right)$, 7.38 (t, 2H, py-H), 7.91 (t, 2H, py-H), 7.97 (d, 2H, ph-H), 8.72 (m, 6H, py-H); ${ }^{13} \mathrm{C}$ NMR (100 MHz, $\left.\mathrm{CDCl}_{3}, \delta, \mathrm{ppm}\right): 19.09$, 119.46, 122.09, 122.82, 124.57, 128.21, 129.11, 136.53, 137.67, 149.71, 150.04, 152.38, 156.61, 166.36; FTIR (KBr): $v=2925-$ 3061, 1730, 1634, 1605, 1584, 1567, 1512, 1469, 1417, 1386, 1214, 1174, 1128, 1038, 875, 788, 729, 660 and $512 \mathrm{~cm}^{-1}$; Anal. Calcd. for $\mathrm{C}_{25} \mathrm{H}_{19} \mathrm{~N}_{3} \mathrm{O}_{2}$ (\%): C, 76.34; N, 10.69; H, 4.83; found: C, 75.98; N, 10.42; H, 4.80.

\subsection{Synthesis of $\boldsymbol{N}$-(vinylbenzylimino) diacetic acid (vbda)}

$N$-(Vinylbenzylimino) diacetic acid was prepared according to the literature (33) and presented as white clusters of needles. Yield: $20 \% .{ }^{1} \mathrm{H}$ NMR (400 MHz, DMSO- $\mathrm{d}_{6}, \delta$, ppm): $3.49\left(\mathrm{~s}, 4 \mathrm{H}, \mathrm{CH}_{2}\right), 3.81\left(\mathrm{~s}, 2 \mathrm{H}, \mathrm{CH}_{2}\right), 5.23\left(\mathrm{~d}, 1 \mathrm{H}, \mathrm{CH}_{2}\right), 5.81(\mathrm{~d}$, $\left.1 \mathrm{H}, \mathrm{CH}_{2}\right), 6.72(\mathrm{~m}, 1 \mathrm{H}, \mathrm{CH}), 7.31$ (d, 2H, ph-H), $7.42(\mathrm{~d}, 2 \mathrm{H}$, ph-H), 12.33 (s, 2H, COOH); ${ }^{13} \mathrm{C}$ NMR (100 MHz, DMSO-d, $\delta, \mathrm{ppm}): 58.81,62.03,119.11,131.26,134.15,141.25,141.66$, 143.73, 177.50; FTIR (KBr): $v=3429,2969-3053,1713,1635$, 1512, 1461, 1408, 1346, 1181, 1108, 961, 879, 831, 675 and 533 $\mathrm{cm}^{-1}$; Anal. Calcd. for $\mathrm{C}_{13} \mathrm{H}_{15} \mathrm{NO}_{4}(\%): \mathrm{C}, 62.65 ; \mathrm{N}, 5.62 ; \mathrm{H}$, 6.02; found: C, 62.88; N, 5.58; H, 6.01.

\subsection{Synthesis of copolymer $\mathrm{P}(\mathrm{mPhtpy}-\mathrm{co}-\mathrm{vbda})$}

The copolymer was synthesized by the RAFT (Reversible Addition Fragmentation chain Transfer) polymerization method. CDB (10.9 mg, $0.04 \mathrm{mmol})$, AIBN (2.2 mg, $0.0133 \mathrm{mmol})$, mPhtpy (0.786 g, $2.0 \mathrm{mmol})$, vbda (0.498 g, 
$2.0 \mathrm{mmol})$ and DMF (8 $\mathrm{ml}$ ) were placed in a dry glass ampoule, and the solution was degassed by three freezeevacuate-thaw cycles. The polymerization was conducted at $70^{\circ} \mathrm{C}$ for $24 \mathrm{~h}$. After rapid cooling by ice water, the mixture was precipitated in a large excess of ethanol and isolated by filtration. The yield was $88.1 \%$. ${ }^{1} \mathrm{H}$ NMR (400 MHz, DMSO-d $\mathrm{d}_{6}, \delta$, ppm): 0.85-2.33 (m, $8 \mathrm{H}, \mathrm{CH}, \mathrm{CH}_{2}$, $\left.\mathrm{CH}_{3}\right), 3.36\left(\mathrm{~s}, 4 \mathrm{H}, \mathrm{CH}_{2}\right), 3.75\left(\mathrm{~s}, 2 \mathrm{H}, \mathrm{CH}_{2}\right), 7.17-9.03(\mathrm{~m}, 18 \mathrm{H}$, py-H, ph-H), 12.41 (s, 2H, COOH); FTIR (KBr): $v=3431$, 2932-3059, 1745, 1603, 1586, 1568, 1509, 1469, 1443, 1418, 1389, 1209, 1169, 1094, 991, 792, 744, 688 and $518 \mathrm{~cm}^{-1}$. The number average molar mass $\left(M_{\mathrm{n}}\right)$ and polydispersity (PDI) obtained in THF $(1.0 \mathrm{ml} / \mathrm{min})$ of the carbonyl groups were converted to methoxycarbonyl units with dicyclohexylcarbodiimide and 4-dimethylaminopyridine. GPC (THF): $M_{\mathrm{w}}=12818, M_{\mathrm{n}}=11627, \mathrm{PDI}=1.10$.

\subsection{Preparation of the bimetallic complexes $\mathrm{P}(\mathrm{mPhtpy}-\mathrm{co}-\mathrm{vbda})-\mathrm{Nd}^{3+}-\mathrm{Co}^{2+}$}

The bimetallic complexes were prepared as follows.

Method 1: The copolymer, $\mathrm{NdCl}_{3} \cdot 6 \mathrm{H}_{2} \mathrm{O}$ and $\mathrm{CoCl}_{2} \cdot 6 \mathrm{H}_{2} \mathrm{O}$ (molar ratio 1:1:1) were dissolved in DMF to a 10\% concentration and stirred at $80^{\circ} \mathrm{C}$ under argon atmosphere for $24 \mathrm{~h}$. The copolymer complex was precipitated by the addition of diethyl ether to the solid-liquid phase mixtures. The precipitate was isolated by filtration and washed with deionized water until the metal ions were removed and then dried at $60^{\circ} \mathrm{C}$ for $24 \mathrm{~h}$ in a vacuum oven. The yield was $61.7 \%$. Co content: $5.84 \%$; $\mathrm{Nd}$ content: $<0.1 \%$.

Method 2: The copolymer and $\mathrm{NdCl}_{3} \cdot 6 \mathrm{H}_{2} \mathrm{O}$ (molar ratio 1:1) were dissolved in DMF to a $10 \%$ concentration and stirred at $80^{\circ} \mathrm{C}$ under argon atmosphere. After $24 \mathrm{~h}$, the DMF solution of $\mathrm{CoCl}_{2} \cdot 6 \mathrm{H}_{2} \mathrm{O}$ (molar ratio with copolymer 1:1) was injected into the mixture via a syringe and stirred for another $24 \mathrm{~h}$. The precipitate was obtained as above. The yield was $63.4 \%$. Co content: $5.81 \%$; Nd content: $2.47 \%$.

Comparing the two methods, it was found that the higher metal content of method 2 was the better approach to synthesize bimetallic complexes.

\subsection{Fabrication of the multilayer film $\left[\mathrm{P}(\mathrm{mPhtpy}-\mathrm{co}-\mathrm{vbda}) / \mathrm{Nd}^{3+} / \mathrm{Co}^{2+}\right]_{20 \times 3}$}

Based on method 2, the multilayer film of $\mathrm{P}(\mathrm{mPhtpy}$-covbda) $/ \mathrm{Nd}^{3+} / \mathrm{Co}^{2+}$ was prepared as follows. $\mathrm{NdCl}_{3} \cdot 6 \mathrm{H}_{2} \mathrm{O}$
$(0.1 \mathrm{~g})$ and $\mathrm{CoCl}_{2} \cdot 6 \mathrm{H}_{2} \mathrm{O}(0.1 \mathrm{~g})$ were, respectively, dissolved in $\mathrm{H}_{2} \mathrm{O}(100 \mathrm{ml})$ to a concentration of $1 \mathrm{mg} / \mathrm{ml}$. $\mathrm{P}(\mathrm{mPhtpy}-$ co-vbda) (0.2 g) was prepared in DMF to a concentration of $2 \mathrm{mg} / \mathrm{ml}$. All procedures were carried out at room temperature. Freshly cleaned PE- $\mathrm{COOH}$ substrate was first immersed into the DMF solution of $\mathrm{P}$ (mPhtpy-co-vbda) for $20 \mathrm{~min}$ and then rinsed three times with DMF for 3 min each time and dried by airflow. The $\mathrm{P}(\mathrm{mPhtpy-co-}$ vbda)-deposited substrate was dipped into the aqueous solution of $\mathrm{NdCl}_{3}$ for $20 \mathrm{~min}$ and rinsed three times with deionized water for 3 min each time and dried by airflow. The substrate was immersed into the aqueous solution of $\mathrm{CoCl}_{2}$ for $20 \mathrm{~min}$, then rinsed three times with deionized water for 3 min each time and dried by airflow. An alternating $\left[\mathrm{P}(\mathrm{mPhtpy}-\mathrm{co}-\mathrm{vbda}) / \mathrm{Nd}^{3+} / \mathrm{Co}^{2+}\right]_{20 \times 3}$ multilayer film can be obtained by repeating these three steps in a cyclic fashion for 20 times. Co content: $2.75 \%$; Nd content: 19.54\%. ATR-IR: $v=3414,1745,1647,1545,1509,1469,1389$, 1215, 1169, 1094, 1015, 792 and $744 \mathrm{~cm}^{-1}$.

\section{Results and discussion}

\subsection{Synthesis of mPhtpy and the vbda monomers}

The monomers were successfully prepared by the synthetic routes outlined in Scheme $1 .{ }^{1} \mathrm{H}$ NMR and ${ }^{13} \mathrm{C}$ NMR spectra were used to identify the structures of the monomers. As can be seen in the ${ }^{1} \mathrm{H}$ NMR spectra (Figure 1A), the single peak at $2.06 \mathrm{ppm}$ is attributed to $\mathrm{CH}_{3}$ and the other two peaks at 5.84 and $6.41 \mathrm{ppm}$ belong to the protons of the vinyl groups $\left(\mathrm{CH}_{2}=\mathrm{C}\right)$ of mPhtpy. For vbda (Figure $\left.1 \mathrm{~B}\right)$, the resonance signal peaks at 5.23, 5.81 and $6.72 \mathrm{ppm}$ belong to the vinyl groups $\left(\mathrm{CH}_{2}=\mathrm{CH}\right)$, and the characteristic peak at $12.33 \mathrm{ppm}$ is attributed to the carboxyl groups
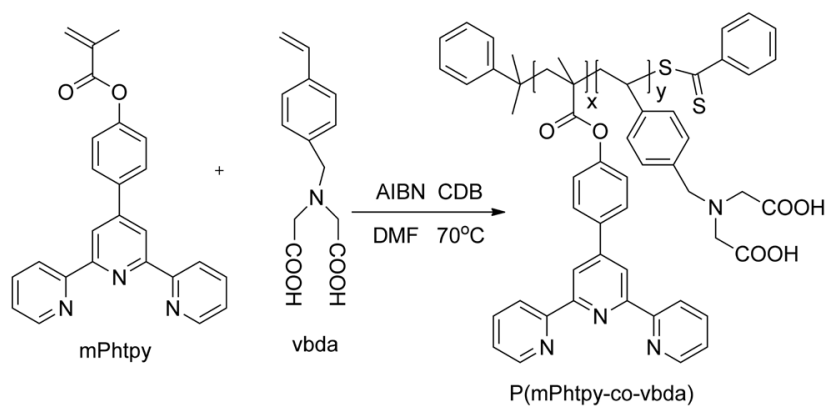

Scheme 1 Synthetic route of the copolymer. 


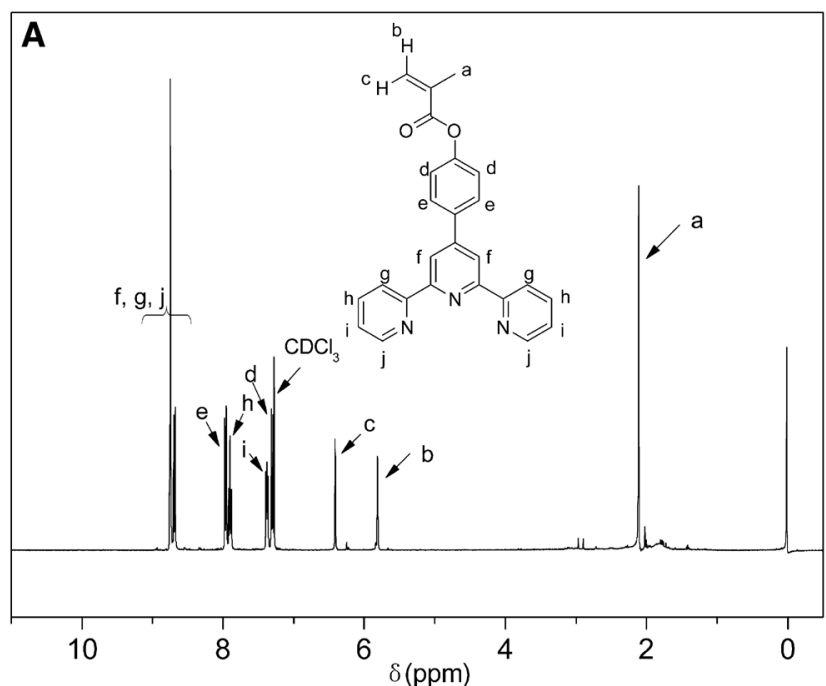

Figure $1{ }^{1} \mathrm{H}$ NMR spectra of mPhtpy (A) and vbda (B).

(COOH). Figure 2 shows the ${ }^{13} \mathrm{C}$ NMR spectra of the monomers mPhtpy and vbda. For mPhtpy (Figure 2A), the peaks at $19.09 \mathrm{ppm}\left(\mathrm{C}^{\mathrm{a}}\right)$ and $128.21 \mathrm{ppm}\left(\mathrm{C}^{\mathrm{c}}\right)$ are attributed to the methyl carbon and methylene carbon of methacrylate, respectively. The peak at $136.53 \mathrm{ppm}\left(\mathrm{C}^{\mathrm{b}}\right)$ belongs to the carbon of the double bond adjacent to the carbonyl group, whereas the peak at $166.36 \mathrm{ppm}\left(\mathrm{C}^{\mathrm{d}}\right)$ is attributed to the carbonyl group. For vbda (Figure 2B), the peaks at $119.11 \mathrm{ppm}\left(\mathrm{C}^{\mathrm{a} \prime}\right)$ and $146.66 \mathrm{ppm}\left(\mathrm{C}^{\mathrm{b}}\right)$ belong to the methylene carbon and methine carbon of vinyl, respectively. The peak at $177.50 \mathrm{ppm}\left(\mathrm{C}^{\mathrm{i}}\right)$ is attributed to the carbonyl groups. These results indicate that the monomers were successfully synthesized.

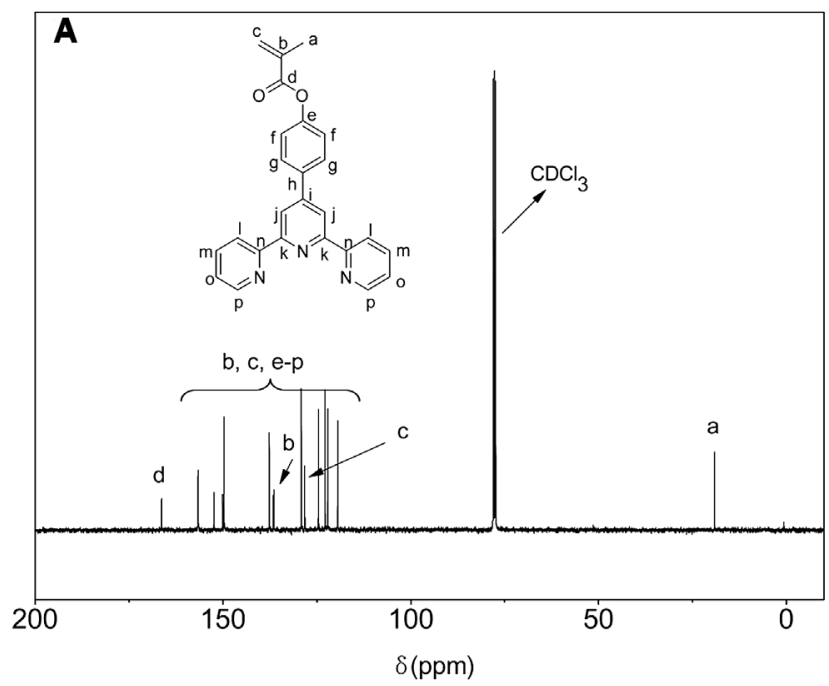

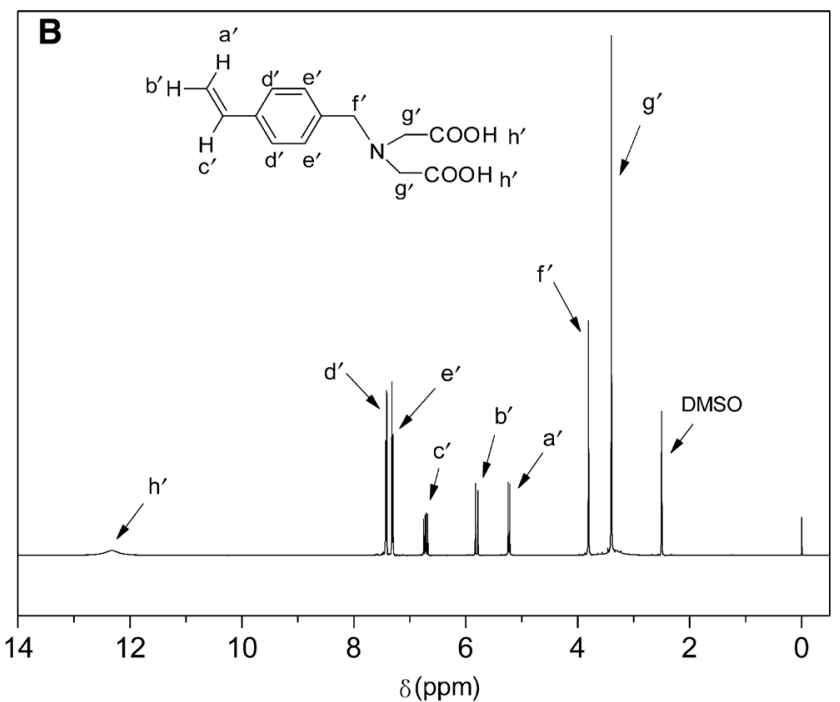

\subsection{Synthesis of the copolymer and polymeric bimetallic complexes}

The synthesis of the copolymer is also shown in Scheme 1. The conversion of the monomers to a copolymer was confirmed by the FTIR and ${ }^{1} \mathrm{H}$ NMR spectra. In the ${ }^{1} \mathrm{H}$ NMR spectra of the copolymer (Figure $3 \mathrm{~A}$ ), the resonance peaks of the vinyl groups $\left(\mathrm{CH}_{2}=\mathrm{C}\right.$ and $\left.\mathrm{CH}_{2}=\mathrm{CH}\right)$ at the range of 5.81-6.72 ppm disappeared completely. The characteristic peak of the carboxyl groups $(\mathrm{COOH})$ shifted from 12.33 to $12.41 \mathrm{ppm}$. With the integration of the peaks for terpyridine and benzene rings of mPhtpy $\left(e^{\prime \prime}-j^{\prime \prime}, k^{\prime \prime}, l^{\prime \prime}, q^{\prime \prime}\right.$ and $r^{\prime \prime}$ in Figure $\left.3 A\right)$ and the peaks for the

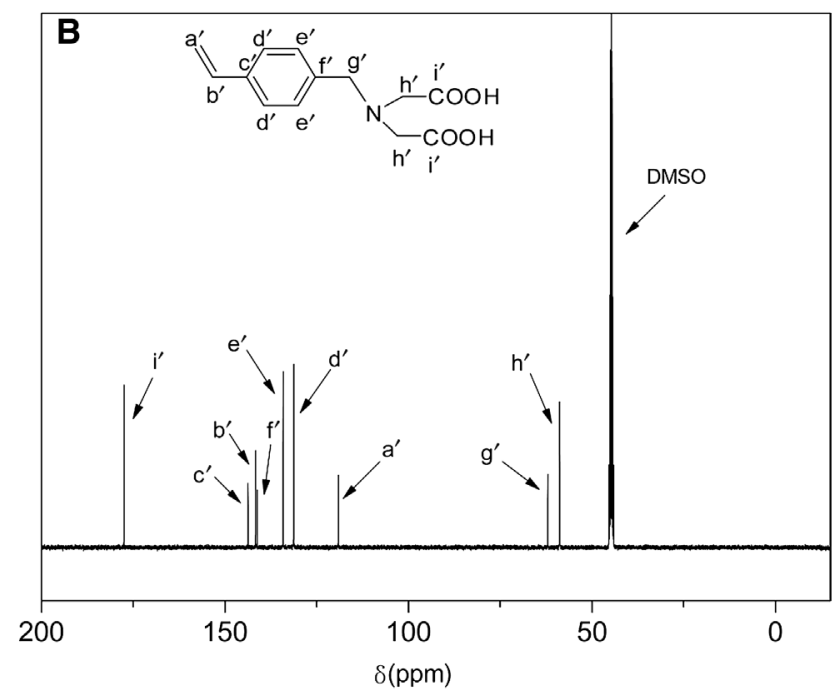

Figure $2{ }^{13} \mathrm{C}$ NMR spectra of mPhtpy (A) and vbda (B). 

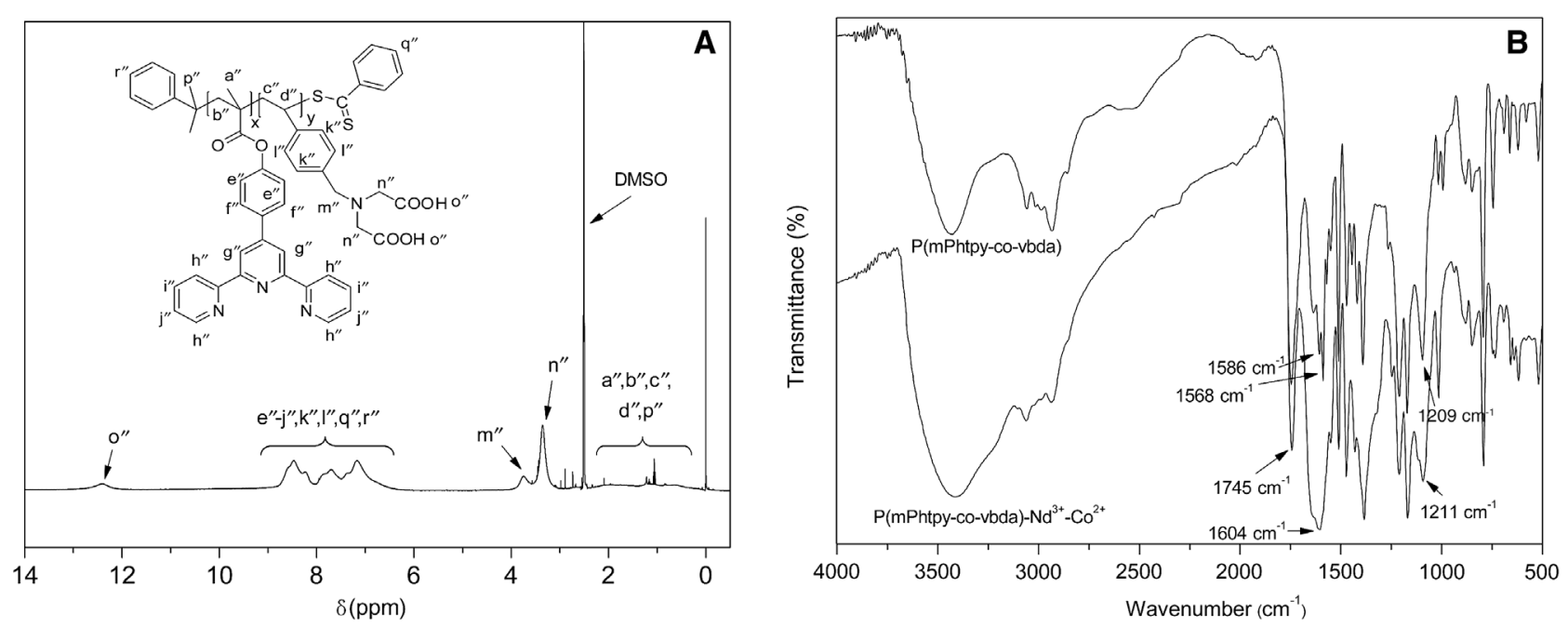

Figure $3{ }^{1 \mathrm{H}}$ NMR spectrum of $\mathrm{P}(\mathrm{mPhtpy}-\mathrm{co}-\mathrm{vbda})(\mathrm{A})$. FT-IR spectra of $\mathrm{P}(\mathrm{mPhtpy}-\mathrm{co}-\mathrm{vbda})$ and $\mathrm{P}(\mathrm{mPhtpy}-\mathrm{co}-\mathrm{vbda})-\mathrm{Nd}^{3+}-\mathrm{Co}^{2+}(\mathrm{B})$.

carboxyl groups (o" in Figure 3A) of vbda, the molar ratio of the mPhtpy and vbda in the random copolymer was calculated to be 2:1.

Based on the metal contents, the molar ratio of mPhtpy and vbda, as well as the structure of the copolymer, we proposed the possible formula in Scheme 2. The metal ions $\left(\mathrm{Co}^{2+}\right.$ and $\left.\mathrm{Nd}^{3+}\right)$ chelated with the nitrogen of the terpyridine ring to form a stable eightmember structure and also chelated with the carboxyl groups in $\mathrm{P}(\mathrm{mPhtpy}-\mathrm{co}-\mathrm{vbda})-\mathrm{Nd}^{3+}-\mathrm{Co}^{2+}$, which is in agreement with the metal contents in the Experimental section. Figure 3B shows the FTIR spectra of the copolymer $\mathrm{P}(\mathrm{mPhtpy}-\mathrm{co}-\mathrm{vbda})$ and the bimetallic complexes $\mathrm{P}(\mathrm{mPhtpy}-\mathrm{co}-\mathrm{vbda})-\mathrm{Nd}^{3+}-\mathrm{Co}^{2+}$. The vibration of the $\mathrm{C}=\mathrm{N}$ bond of the terpyridine ring of the copolymer shifted from 1586 to $1604 \mathrm{~cm}^{-1}$ and changed to a broad peak for the complexes (34). The uncoordinated COO stretching band occurred at $1745 \mathrm{~cm}^{-1}$ in the copolymer, whereas the coordinated $\mathrm{COO}$ stretching band was at $1604 \mathrm{~cm}^{-1}$ for the complexes (35).

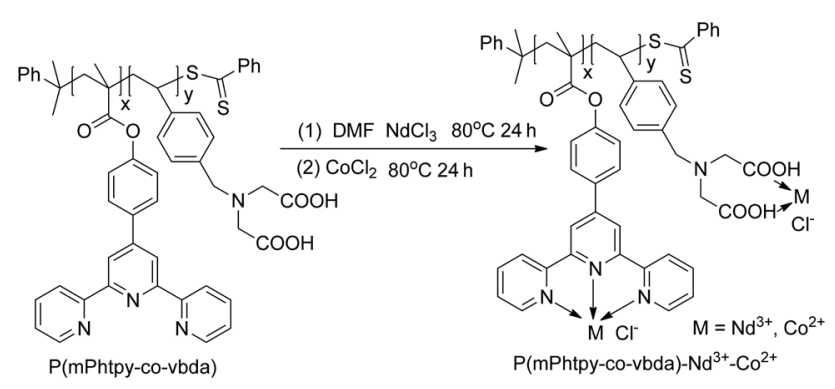

Scheme 2 Suggested structures of the bimetallic complexes.

\subsection{Structural and optical characterization of the film}

The multilayer film was characterized by UV-Vis and ATR-IR spectroscopy. The alternating deposition and optical features were monitored by UV-Vis spectroscopy. Figure 4A shows the UV-Vis absorption spectra of the multilayer film consisting of $\mathrm{P}$ (mPhtpy-co-vbda) and metal ions $\left(\mathrm{Nd}^{3+}\right.$ and $\left.\mathrm{Co}^{2+}\right)$ with different numbers of layers on a PE-COOH substrate. The optical density of the characteristic multilayer band at $287 \mathrm{~nm}$ is a function of layer numbers (linear correlation in Figure 4A, inset), indicating a constant number of layers at each stage. However, the linear correlation was an imperfection of the monolayer and the second layer absorption probably because of the H-bonding attraction of the initial deposition between the copolymer and the PE-COOH substrate (36) and of the instability of the coordination between the copolymer and the metal ions.

The covalent coordination (37) as a driving force for preparing the multilayer film was identified by ATR-IR spectroscopy. Figure 4B shows the ATR-IR spectra of the $\mathrm{PE}-\mathrm{COOH}$ film and the multilayer films with different layers: $\left[\mathrm{P}(\mathrm{mPhtpy}-\mathrm{co}-\mathrm{vbda}) / \mathrm{Nd}^{3+} / \mathrm{Co}^{2+}\right]_{4 \times 3},[\mathrm{P}(\mathrm{mPhtpy}-\mathrm{co}-$ vbda $\left.) / \mathrm{Nd}^{3+} / \mathrm{Co}^{2+}\right]_{8 \times 3}, \quad\left[\mathrm{P}(\mathrm{mPhtpy}-\mathrm{co}-\mathrm{vbda}) / \mathrm{Nd}^{3+} / \mathrm{Co}^{2+}\right]_{12 \times 3}$, $\left[\mathrm{P}(\mathrm{mPhtpy}-\mathrm{co}-\mathrm{vbda}) / \mathrm{Nd}^{3+} / \mathrm{Co}^{2+}\right)_{16 \times 3}$ and $[\mathrm{P}(\mathrm{mPhtpy}-\mathrm{co}-$ vbda) $\left./ \mathrm{Nd}^{3+} / \mathrm{Co}^{2+}\right]_{20 \times 3^{\circ}}$. After the PE film was oxidized, the sample with an absorption peak of carboxyl at $1710 \mathrm{~cm}^{-1}$ exhibited the hydrophilic surface for assembly. All the ATR-IR spectra had similar peaks at 2917, 2849, 1473 and $731 \mathrm{~cm}^{-1}$, which were attributed to the vibration of $\mathrm{C}-\mathrm{H}$ of the polyethylene substrate. The peak at $1647 \mathrm{~cm}^{-1}$ was 

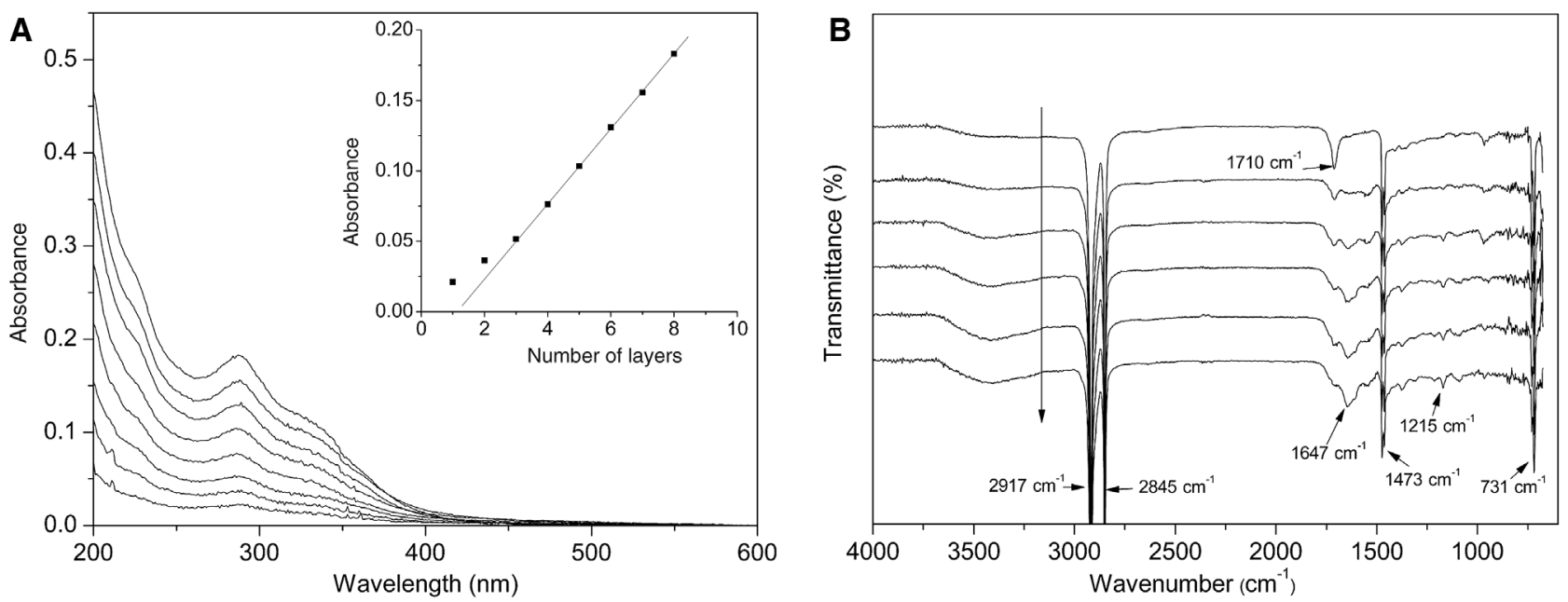

Figure 4 UV-Vis absorption spectra of one to eight layers (from the lower to the upper curves) of the multilayer film $\mathrm{P}(\mathrm{mPhtpy}$-co-vbda)/ $\mathrm{Nd}^{3+} / \mathrm{CO}^{2+}$. The inset shows the absorbance at $287 \mathrm{~nm}$ vs. the number of layers (A). ATR-IR spectra (from the upper to the lower curves) of $\mathrm{PE}-\mathrm{COOH}$ having a clear carbonyl band at $1710 \mathrm{~cm}^{-1}$ and the multilayer film $\left[\mathrm{P}(\mathrm{mPhtpy}-\mathrm{co}-\mathrm{vbda}) / \mathrm{Nd}^{3+} / \mathrm{Co}^{2+}\right]_{n \times 3}(n=4,8,12,16,20) \mathrm{being}$ in the region from 700 to $4000 \mathrm{~cm}^{-1}(\mathrm{~B})$.

related to the terpyridinyl ring and carboxyl functional groups. The results showed that the peak at $1586 \mathrm{~cm}^{-1}$ for the vibration of the $\mathrm{C}=\mathrm{N}$ bond of the copolymer shifted to $1647 \mathrm{~cm}^{-1}$ (34), whereas the uncoordinated COO stretching band at $1745 \mathrm{~cm}^{-1}$ obviously shifted to $1647 \mathrm{~cm}^{-1}$ after the coordination (35). Such shifts demonstrated that the ligands, the terpyridinyl and carboxyl groups, formed stable complexes with the metal ions $\left(\mathrm{Nd}^{3+}\right.$ and $\left.\mathrm{Co}^{2+}\right)$. Compared with the FTIR spectrum of the complexes $\mathrm{P}(\mathrm{mPhtpy}-\mathrm{co}-\mathrm{vbda})-\mathrm{Nd}^{3+}-\mathrm{Co}^{2+}$ (Figure 3B), the characteristic absorption peak of $\mathrm{C}=\mathrm{N}$ and $\mathrm{COO}$ changed more remarkably because most of the ligands were coupled with $\mathrm{Nd}^{3+}$ and the rest were chelated with $\mathrm{Co}^{2+}$ in the assembly process. This is also consistent with the measurement of the metal contents.

\subsection{Magnetic properties of the copolymer complexes and the thin film}

The magnetic behaviors of the copolymer complexes and the thin film were determined by a PPMS magnetometer. Figure 5 shows the temperature dependence of the magnetization $(M)$ of the complexes $\mathrm{P}(\mathrm{mPhtpy}$ co-vbda) $-\mathrm{Nd}^{3+-} \mathrm{Co}^{2+}$ and the film $[\mathrm{P}(\mathrm{mPhtpy}-\mathrm{co}-\mathrm{vbda}) /$ $\left.\mathrm{Nd}^{3+} / \mathrm{Co}^{2+}\right]_{20 \times 3}$ at an applied magnetic field of $30 \mathrm{kOe}$ from 5 to $300 \mathrm{~K}$. For both the complexes and the film, positive magnetization decreased sharply as the temperature increased when it was below $50 \mathrm{~K}$ and then decreased slowly.
To obtain a complete information about the magnetization of the complexes $\mathrm{P}(\mathrm{mPhtpy}-\mathrm{co}-\mathrm{vbda})-\mathrm{Nd}^{3+}-\mathrm{Co}^{2+}$ and the film $\left[\mathrm{P}(\mathrm{mPhtpy}-\mathrm{co}-\mathrm{vbda}) / \mathrm{Nd}^{3+} / \mathrm{Co}^{2+}\right]_{20 \times 3}$, the magnetic hysteresis loops were detected. Figure 6 shows the magnetic hysteresis loops of the copolymer complexes and the thin film at $5 \mathrm{~K}$. The observed coercive field $\left(H_{c}\right)$ of the complexes and the film was 1.7 and 0 Oe, respectively (Figure 6A and B inset). The remnant magnetization $\left(M_{\mathrm{r}}\right)$ of the complexes and the film was 0.03 and $0 \mathrm{emu} / \mathrm{g}$, respectively. The similar "S" shape and such low $H_{c}$ and $M_{\mathrm{r}}$ indicate that the complexes $\mathrm{P}\left(\mathrm{mPh}\right.$ tpy-co-vbda) $-\mathrm{Nd}^{3+}-\mathrm{Co}^{2+}$ and the film $[\mathrm{P}(\mathrm{mPhtpy}-\mathrm{co}$ -vbda) $\left./ \mathrm{Nd}^{3+} / \mathrm{Co}^{2+}\right]_{20 \times 3}$ were soft ferromagnetic materials.

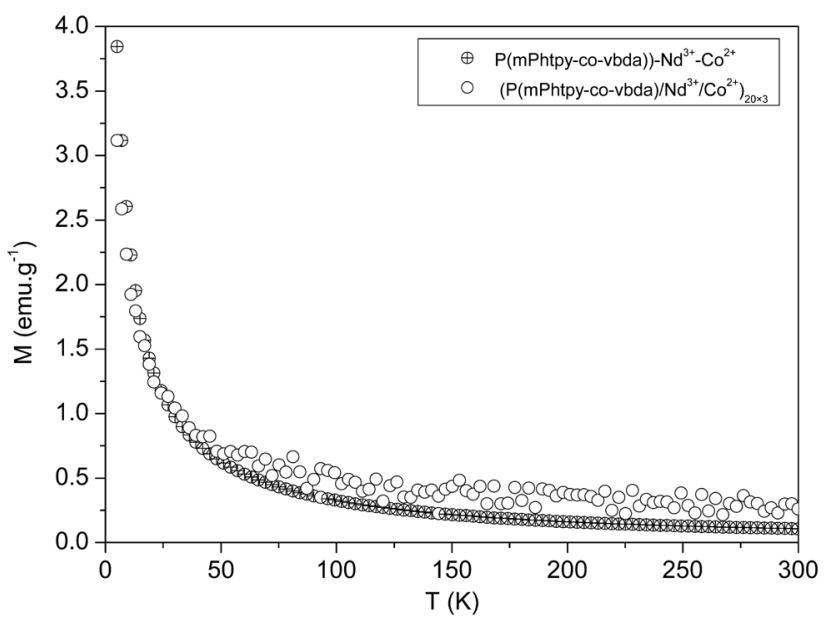

Figure 5 Temperature dependence of magnetization $(M)$ for the complexes and the film at $H=30 \mathrm{kOe}$. 

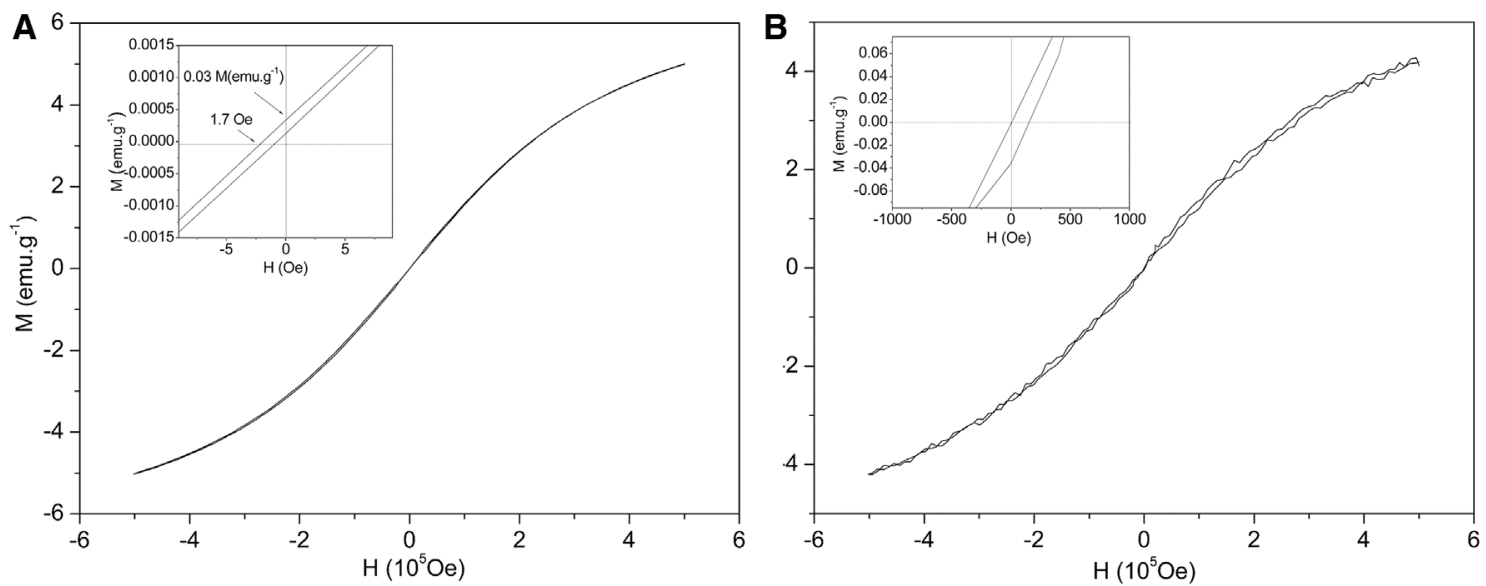

Figure 6 Hysteresis loop ( $M$ vs. $H$ ) at $5 \mathrm{~K}$ for the complexes (inset: expanded view of the region from -10 to 10 Oe) (A). Hysteresis loop ( $M$ vs. $H)$ at $5 \mathrm{~K}$ for the film (inset: expanded view of the region from -1000 to1000 0e) (B).

\section{Conclusions}

In summary, we synthesized a copolymer $\mathrm{P}(\mathrm{mPhtpy}$-covbda) and its complexes $\mathrm{P}\left(\mathrm{mPh}\right.$ tpy-co-vbda) $-\mathrm{Nd}^{3+}-\mathrm{Co}^{2+}$ as well as prepared a magnetic multilayer thin film $[\mathrm{P}(\mathrm{mPhtpy}-$ co-vbda) $\left./ \mathrm{Nd}^{3+} / \mathrm{Co}^{2+}\right]_{20 \times 3}$ via the LbL self-assembly approach. The optical properties of the film were first investigated by ATR-IR and UV-Vis spectroscopy. Moreover, the low $H_{\mathrm{c}}$ and $M_{\mathrm{r}}$ and an "S"-shape hysteresis loop of the complexes and the film indicated that both the complexes and the film were soft ferromagnetic materials. It is expected that the magnetic multilayer thin film could be fabricated for delicate magnetic devices under a complicated environment.

Acknowledgments: The authors are grateful for the financial support from the National Natural Science Foundation of China (grant no. 21174129) and the Program for Zhejiang Leading Team of S\&T Innovation (grant no. 2011R50007).

\section{References}

1. Decher G. Fuzzy nanoassemblies: toward layered polymeric multicomposites. Science 1997;277(5330):1232-37.

2. Lin WH, Sun WL, Yang J, Sun QH, Shen ZQ. Fabrication of magnetic thin films by a layer-by-layer self-assembly approach. J Phys Chem C. 2009;113(39):16884-95.

3. Ariga K, Yamauchi Y, Rydzek G, Ji Q, Yonamine Y. Layer-by-layer nanoarchitectonics: invention, innovation, and evolution. Chem Lett. 2014;43(1):36-68.

4. Lin WH, Sun WL, Yang J, Shen ZQ. Preparation and magnetic properties of multilayer films based on self-assembly. J Phys Chem C. 2008;112(46):18217-23.

5. Morgan GT, Burstall FH. Researches on residual affinity and coordination. Part XXXVII. Complex metallic salts containing 2:6-di-2' pyridyl-pyridine (2:2':2"- tripyridyl). J Chem Soc. 1937:1649-55.
6. Wu KQ, Guo J, Yan JF, Xie LL, Xu FB, Bai S, Nockemann P, Yuan YF. Ruthenium(II) bis(terpyridine) electron transfer complexes with alkynyl-ferrocenyl bridges: synthesis, structures, and electrochemical and spectroscopic studies. Dalton Trans. 2012;41(36):11000-08.

7. Harihara P, Mohan R, Dhananjaya P, Rudrakanta S, Murali KP, Chu HC, Chu CW, Wei KH, Lin HC. Synthesis of main-chain metallo-copolymers containing donor and acceptor bis-terpyridyl ligands for photovoltaic applications. Macromol Rapid Commun. 2012;33(6):528-33.

8. Padhi SK, Saha D, Sahu R, Subramanian J, Manivannan V. Synthesis, structure, optical and magnetic properties of $\left[\mathrm{CrL}(\mathrm{X})_{3}\right],\left\{\mathrm{L}=4^{\prime}\right.$-(2-pyridyl)-2,2': $6^{\prime}, 2^{\prime \prime}$ - terpyridine; $\mathrm{X}=\mathrm{Cl} ; \mathrm{N}_{3}$; $\mathrm{NCS}-$. Polyhedron 2008;27(6):1714-20.

9. Manuel GC, Tato F, Buñuel E, Calle P, Cárdenas D. Fe-catalysed Kumada-type alkyl-alkyl cross-coupling. Evidence for the intermediacy of Fe(I) complexes. J Chem Sci. 2013;4(3):1098-104.

10. Anthonysamy A, Balasubramanian S, Shanmugaiah V, Mathivanan N. Synthesis, characterization and electrochemistry of $4^{\prime}$-functionalized $2,2^{\prime}: 6^{\prime}, 2^{\prime \prime}$-terpyridine ruthenium(II) complexes and their biological activity. Dalton Trans. 2008;(16):2136-43.

11. Bolink HJ, Capelli L, Coronado E, Gavina P. Observation of electroluminescence at room temperature from a ruthenium(II) bis-terpyridine complex and its use for preparing light-emitting electrochemical cells. Inorg Chem. 2005;44(17):5966-68.

12. Rawling T, Austin C, Buchholz F, Colbran SB, McDonagh AM. Ruthenium phthalocyanine-bipyridyl dyads as sensitizers for dye-sensitized solar cells: dye coverage versus molecular efficiency. Inorg Chem. 2009;48(7):3215-27.

13. Chan YT, Li S, Moorefield CN, Wang P, Shreiner CD, Newkome GR. Self-assembly, disassembly, and reassembly of gold nanorods mediated by bis(terpyridine)-metal connectivity. Chem Eur J. 2010;16(14):4164-68.

14. Duffort V, Thouvenot R, Afonso C, Izzet G, Proust A. Straightforward synthesis of new polyoxometalate-based hybrids exemplified by the covalent bonding of a polypyridyl ligand. Chem Commun. 2009;(40):6062-64.

15. Kubo W, Nagao M, Otsuka Y, Homma T, Miyata H. Formation of multinuclear metal-terpyridyl complexes covalently bound to carbon substrates. Langmuir 2009;25(23):13340-43. 
16. Pan YX, Tong B, Shi JB, Zhao W, Shen JB, Zhi J, Dong YP. Fabrication, characterization, and optoelectronic properties of layer-by-layer films based on terpyridine-modified MWCNTs and ruthenium(III) ions. J Phys Chem C. 2010;114(17):8040-47.

17. Gao YH, Wu JY, Zhao Q, Zheng LX, Zhou HP, Zhang SY, Yang JX, Tian YP. Solvent-resolved fluorescent Ag nanocrystals capped with a novel terpyridine- based dye. New J Chem. 2009;33(3):607-11.

18. Haensch C, Chiper M, Ulbricht C, Winter A, Hoeppener S, Schubert US. Reversible supramolecular functionalization of surfaces: terpyridine ligands as versatile building blocks for noncovalent architectures. Langmuir 2008;24(22):12981-85.

19. Kurita T, Nishimori Y, Toshimitsu F, Muratsugu S, Kume S, Nishihara $\mathrm{H}$. Surface Junction effects on the electron conduction of molecular wires. J Am Chem Soc. 2010;132(13):4524-25.

20. Smith HL, Usala RL, McQueen EW, Goldsmith JI. Novel polyaromatic-terminated transition metal complexes for the functionalization of carbon surfaces. Langmuir 2010;26(5):3342-49.

21. Ueki T, Takasaki Y, Bundo K, Ueno T, Sakai T, Akagi Y, Yoshida R. Autonomous viscosity oscillation via metallo-supramolecular terpyridine chemistry of branched poly(ethylene glycol) driven by the Belousov-Zhabotinsky reaction. Soft Matter. 2014;10(9):1349-55.

22. Konno T, Koide K, Ishida T. A supramolecular switch between ground high- and low-spin states using 2, 2':6', $2^{\prime \prime}$-terpyridine6,6-diyl bis(tert-butyl nitroxide). Chem Commun. 2013;49(45): 5156-58.

23. Chaberek S, Martel AE. Stability of metal chelates: I. iminodiacetic and iminodipropionic acids. J Am Chem Soc. 1952;74(20):5052-56.

24. Thompson LC. Complexes of the rare earths: I. iminodiacetic acid. Inorg Chem. 1961;1(3):490-93.

25. Tang JB, Jiang LM, Sun WL, Shen ZQ. Synthesis of poly(thiazole2,4-diyl)-rare-earth complexes and their magnetic properties. React Funct Polym. 2004;61(3):405-10.

26. Sun WL, Jiang LM, Weng J, He BJ, Cen DQ, Shen ZQ. A novel bithiazole-tetrathiapentalene polymer and its metal complexes. React Funct Polym. 2003;55(3):249-54.

27. Ding NW, Sun WL, Lin Y, Shen ZQ. Synthesis and magnetic properties of the novel complexes of a conjugated hyper- branched polymer containing bithiazole ring. Chin J Polym Sci. 2012;30(5):759-69.

28. Lin WH, Sun WL, Yang J, Shen ZQ. Preparation and magnetic properties of novel supramolecular complexes containing bithiazole rings. Mater Chem Phys. 2008;112(46):617-23.

29. Rasmussen JR, Stedronsky ER, Whitesides GM. Introduction, modification, and characterization of functional groups on the surface of low-density polyethylene film. J Am Chem Soc. 1977;99(14):4736-45.

30. Moad G, Chiefari J, Chong YK, Krstina J, Mayadunne RT, Postma A, Rizzardo E, Thang SH. Living free radical polymerization with reversible addition - fragmentation chain transfer (the life of RAFT). Polym Int. 2000;49(9):993-1001.

31. Sun LN, Zhang HJ, Yu JB, Yu SY, Peng CY, Dang S, Guo XM, Feng J. Near-infrared emission from novel tris(8-hydroxyquinolinate) lanthanide(III) complexes-functionalized mesoporous SBA-15. Langmuir 2008;24(10):5500-7.

32. Luo J, Wang YH, Ren R, Sun WL, Shen ZQ. Designed magnetic multilayer thin films fabricated via layer-by-layer assembly of polycyanofullerenes. J Appl Polym Sci. 2014;131(17): 40681-87.

33. Morris LR, Mock RA, Marshall CA, Howe JH. Synthesis of some amino acid derivatives of styrene. J Am Chem Soc. 1959;81(2): 377-81.

34. Strukl JS, Walter JL. Infrared and Raman spectra of heterocyclic compounds - IV. The infrared studies and normal vibrations of some 1:I transition metal complexes of 2,2'- bipyridine. Spectrochim Acta 1971;28(2):223-38.

35. Nakamoto K. Infrared and Raman spectra of inorganic and coordination compounds: Part B. Applications in coordination, organometallic, and bioinorganic chemistry, 6th edition. New Jersey: Wiley; 2010. pp. 72-3.

36. Guzman E, Ritacco H, Rubio JE, Rubio RG, Ortega F. Saltinduced changes in the growth of polyelectrolyte layers of poly(diallyldimethylammonium chloride) and poly(4-styrene sulfonate of sodium). Soft Matter 2009;5(10):2130-42.

37. Xiong HM, Cheng MH, Zhou Z, Zhang X, Shen JC. A new approach to the fabrication of a self-organizing film of heterostructured polymer/ $\mathrm{Cu}_{2} \mathrm{~S}$ nanoparticles. Adv Mater. 1998;10(7):529-32. 